\title{
Mobile Phone: A Smart and Healthy Device
}

\author{
Article by Sunaina Sharma \\ Maharaja Agrasen Institution of Technology, Maharaja Agrasen University, Baddi, India \\ E-mail: Sunaina.sh39@gmail.com
}

\begin{abstract}
Research into health communication seeks to refine communication strategies to inform people about ways to enhance health or to avoid specific health risks. As per many reports, current scenarios the health risks are generally like Cardiac arrest, Blood pressure, Sugar etc. This paper proposes a Smart Wrist Watch which will measure the Blood pressure, sugar and Pulse rate of the individual and if risk has been found it will inform the group of persons with the location of the mobile.
\end{abstract}

Keywords: Health Communication, Mobile health, Smart Watch, Healthy app, Wrist Watch BP monitor, Wrist Watch Glucose monitor \& Wrist Watch pulse rate monitor.

\section{Introduction}

The health and the safety of people must be taken into account with high answerability. In India most of the deaths are due to delay in first aid or absence of first aid. Even sometimes it happen that person sleeping at night found lifeless in morning. If contraption would be developed such incidence can be reduced to a great extent. Presently, India has the largest number of mobile users. If the mobile phone can be smart phone then why not healthy phone? How about, if mobile phone gives message to near once and doctor that there is something wrong with its user, also informs the Location of the user. The aim of the paper is to minimize the involuntary loss of life. Here, two units have been proposed which are as follows:

Smart Wrist Watch: This will measure the signal and transmit it to the mobile unit.

Mobile Application (Healthy App): It will be installed in the mobile unit. In this application the reference value will be fed by the user manually. The reference value is fed manually because the value of these parameters varies from person to person. After receiving the signal from the watch, it will compare this value with the reference value. If the difference is great then critical it will be treated as serious matter and an emergency will be transferred to the group of people. If the difference is less than critical level a warning message will be send to the user, which will remind the user to take the medicine and if there is no difference then the process will continue. 
DOI: $10.21522 /$ TIJAR.2014.04.02.Art026

ISSN: $2520-3088$

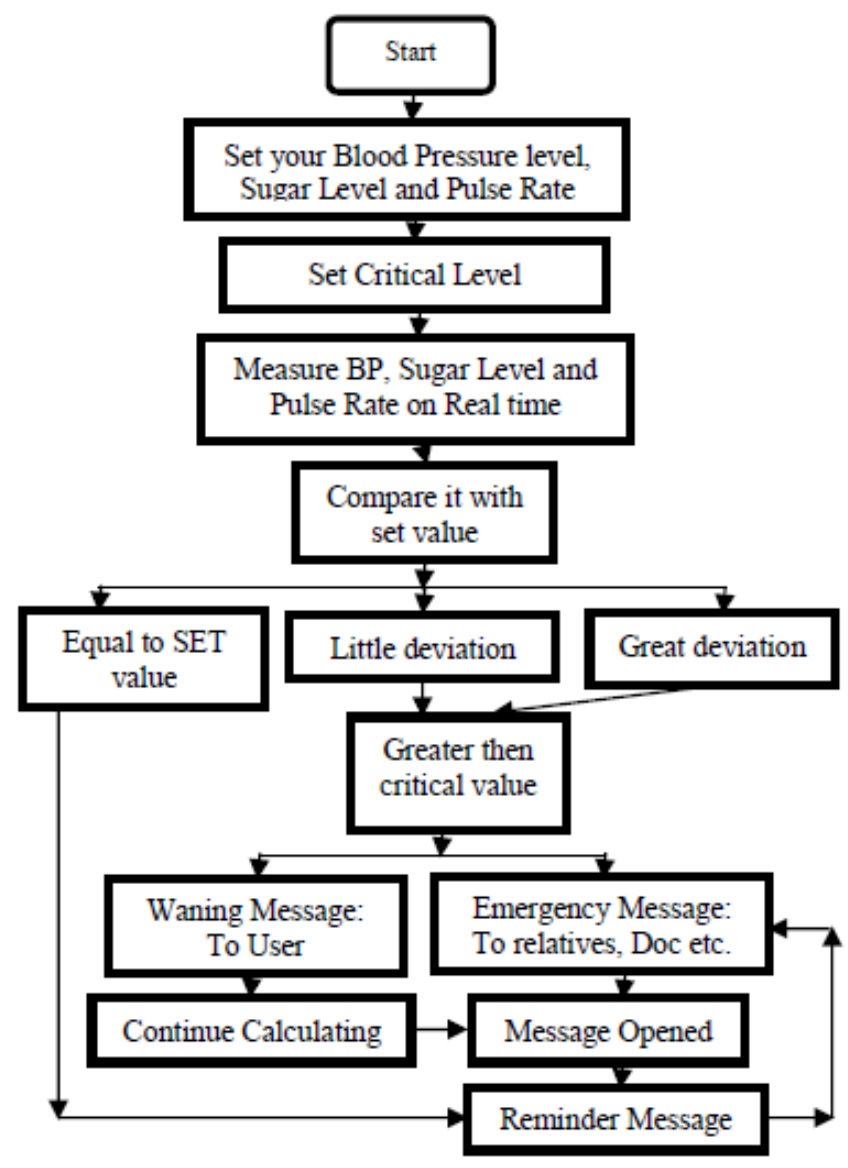

Figure 1. Flow chart showing processing of software

Case Study: As mentioned earlier it needs two main things

1. Smart Wrist watch

2. Mobile application (healthy app).

In starting user need to have the smart wrist watch and install healthy app. The "Smart" word is used because this wrist watch will measure the glucose level, blood pressure and pulse rate instead of showing time. The watch act like a transducer and measure the above said parameters on real time basis. This smart watch is connected to mobile phone via internet. It is important to note here $24 \times 7$ that Internet connection is mandatory for this app. Once the reading has been taken it is send to the application in mobile phone. Here, each value i.e. glucose level, blood pressure and pulse rate is compared with their reference value (as mentioned earlier reference value of each parameter is entered manually in mobile app in starting phase). The result is than compared with the critical value. After comparing based on the result there are three cases: For Example: Consider four persons Mr. ABC, Ms. XYZ, Mr. PQR and Ms. DEF is using the app. Mr. ABC is a healthy person with normal pulse rate, blood pressure and glucose level, while Ms. XYZ is suffering from hypertension and diabetes due to which her pulse rate also increases sometimes, Mr. PQR's blood pressure switches rapidly and Ms. DEF is suffering diabetes. They have set the reference level as under:

Table1. Reference Value Table

\begin{tabular}{|l|l|l|l|l|}
\hline Particulars & Mr. ABC & Ms. XYZ & Mr. PQR & Ms. DEF \\
\hline $\begin{array}{l}\text { Blood Pressure } \\
\text { (Systolic/Diastolic) }\end{array}$ & $80-120$ & $120-160$ & $70-120$ & $80-120$ \\
\hline Pulse Rate (per minute) & 78 & 100 & 90 & 75 \\
\hline Glucose Level (mg/dl) & 160 & 200 & 172 & 205 \\
\hline
\end{tabular}


And the critical level as under: * Single vale or range of value

Table 2. Critical value table

\begin{tabular}{|l|l|l|l|l|}
\hline Particulars & Mr. ABC & Ms. XYZ & Mr. PQR & Ms. DEF \\
\hline $\begin{array}{l}\text { Blood Pressure } \\
\text { (Systolic/Diastolic) }\end{array}$ & $60-140$ & $140-180$ & $60-140$ & $60-140$ \\
\hline Pulse Rate (per minute) & 90 & 115 & 110 & 100 \\
\hline Glucose Level (mg/dl) & 190 & 215 & 190 & 215 \\
\hline
\end{tabular}

Case 1: If there is either no difference or less difference between the reference value and the reading taken, that means the situation is normal. No need to do anything. The app will work in background.

Case 2: If the difference is less: Suppose a case when Mr. ABC's Blood pressure shoots up to 90140 and the rest thing are normal. But it situation is normal nothing to panic. It can be due to heavy exercise and Mr. ABC has already set the emergency level to 140. So this case will be considered as normal case and a warning message will prompt to let the user know about it. At the same time Ms. $\mathrm{XYZ}$ is suffering from hypertension is rise in his BP can be a serious problem. In Mr. ABC case 20 rises in $\mathrm{BP}$ cause no issue, but 20 rise in Mr. XYZ will cause problem. Since then only a message will be forwarded to the user to take precautions to avoid the state of affairs. This message can also help him to remind him to take medicine, if forgotten.

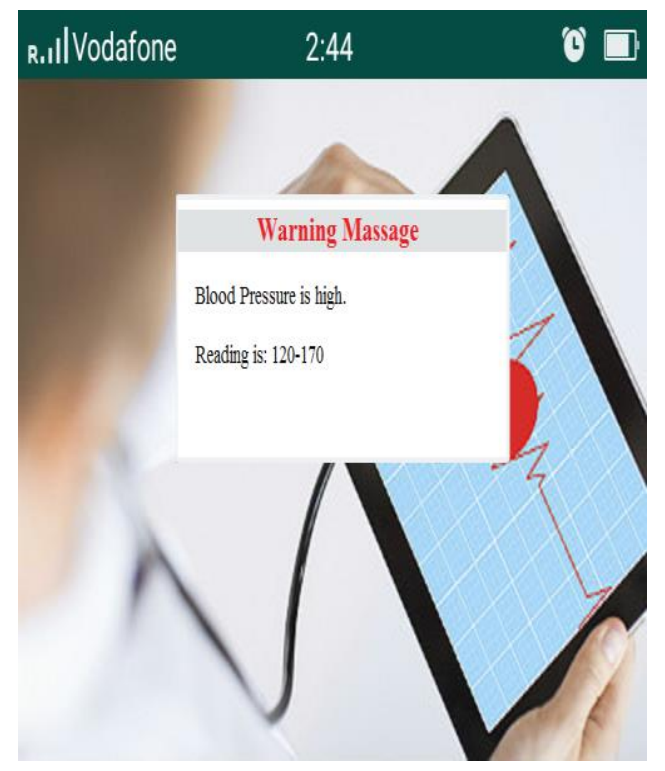

Figure 1. Screenshot of warning message at user's mobile

Case3: As Mr. PQR is suffering from blood pressure. His blood pressure switched between low and high and Ms. DEF is suffering from sugar. It will be difficult for both of them to take any medicine without checking. In both the cases the smart watch will help them. Suppose Mr. PQR BP rises to 140-190 and Ms. DEF's rises to 220 which is dangerous level. So the machine will locate the position of the user and send the emergency message with the current location of the user to its near once. 
DOI: $10.21522 /$ TIJAR.2014.04.02.Art026

ISSN: $2520-3088$

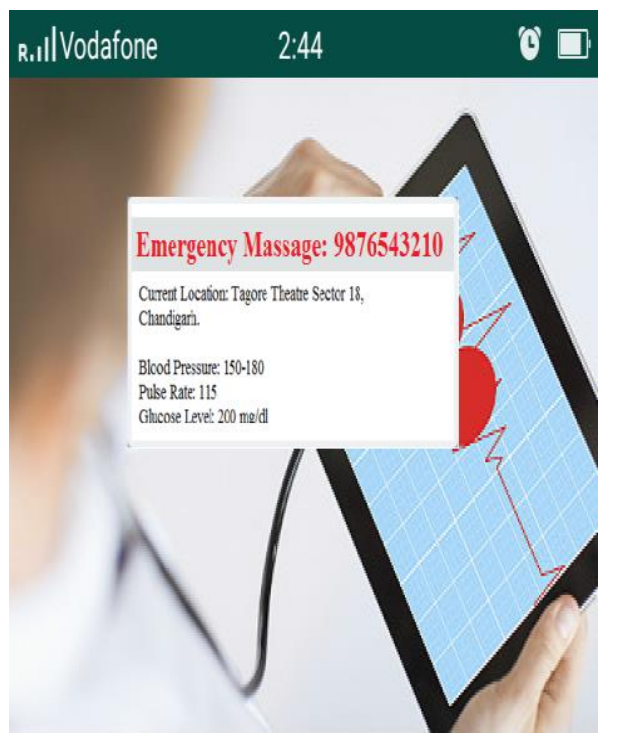

Figure 2. Screenshot of emergency message at user's mobile.

Table3. Showing deviation

\begin{tabular}{|l|l|l|l|}
\hline Particulars & Case 1 & Case 2 & Case 3 \\
\hline $\begin{array}{l}\text { Blood } \\
\text { Pressure }\end{array}$ & $\begin{array}{l}\text { Little } \\
\text { Deviation }\end{array}$ & $\begin{array}{l}\text { No } \\
\text { deviation }\end{array}$ & $\begin{array}{l}\text { Critical } \\
\text { Value }\end{array}$ \\
\hline Pulse Rate & $\begin{array}{l}\text { Little } \\
\text { Deviation }\end{array}$ & $\begin{array}{l}\text { No } \\
\text { deviation }\end{array}$ & $\begin{array}{l}\text { Critical } \\
\text { Value }\end{array}$ \\
\hline $\begin{array}{l}\text { Sugar } \\
\text { Level }\end{array}$ & $\begin{array}{l}\text { Little } \\
\text { Deviation }\end{array}$ & $\begin{array}{l}\text { No } \\
\text { deviation }\end{array}$ & $\begin{array}{l}\text { Critical } \\
\text { Value }\end{array}$ \\
\hline
\end{tabular}

Note: The application will continue to give reminder message until the message is open because if the message remains unread the objective of the machine will defeat.

How does it work: In beginning the user ties the wrist watch on his/her arm and set the both reference level and critical level according to his requirement. After that the wrist watch will start measuring all the three things. And send the signal to mobile phone via Bluetooth/wifi

And the results are as under:

Table 4. Deviation from Reference value

\begin{tabular}{|l|l|l|l|l|l|l|l|}
\hline Sr. No & Name & $\begin{array}{l}\text { Diagnosti } \\
\text { c }\end{array}$ & BP level & $\begin{array}{l}\text { Glucose } \\
\text { Level }\end{array}$ & Pulse & Action & Remarks \\
\hline 1. & All* & Normal & Normal & Normal & Normal & No action & $\begin{array}{l}\text { Continue to } \\
\text { work in } \\
\text { background }\end{array}$ \\
\hline $\mathbf{2 .}$ & $\begin{array}{l}\text { Mr. } \\
\text { ABC }\end{array}$ & Normal & $\begin{array}{l}\text { BP rise } \\
(90-140)\end{array}$ & Normal & Normal & $\begin{array}{l}\text { BP rises } \\
\text { between } \\
\text { critical } \\
\text { level: } \\
\text { Warning } \\
\text { Message }\end{array}$ & $\begin{array}{l}\text { Critical } \\
\text { Level is } \\
\text { (90-140) }\end{array}$ \\
\hline $\mathbf{3 .}$ & $\begin{array}{l}\text { Ms. } \\
\text { XYZ }\end{array}$ & $\begin{array}{l}\text { Hypertens } \\
\text { ion }\end{array}$ & $\begin{array}{l}\text { Hypertens } \\
\text { ion (120- } \\
160)\end{array}$ & Normal & Normal & $\begin{array}{l}\text { General BP } \\
\text { is high: } \\
\text { Warning } \\
\text { Message }\end{array}$ & $\begin{array}{l}\text { Critical } \\
\text { Level is } \\
(140-180)\end{array}$ \\
\hline 4. & $\begin{array}{l}\text { Mr. } \\
\text { PQR }\end{array}$ & $\begin{array}{l}\text { Hypertens } \\
\text { ion/ } \\
\text { Hypotensi }\end{array}$ & $\begin{array}{l}\text { Hypertens } \\
\text { ion }(140- \\
190)\end{array}$ & Normal & $\begin{array}{l}\text { High } \\
(110)\end{array}$ & $\begin{array}{l}\text { BP \& PR } \\
\text { high: } \\
\text { Emergency }\end{array}$ & $\begin{array}{l}\text { Blood } \\
\text { pressure } \\
\text { switches. }\end{array}$ \\
\hline
\end{tabular}


Texila International Journal of Academic Research Volume 4, Issue 2, Dec 2017

\begin{tabular}{|l|l|l|l|l|l|l|l|}
\hline & & on & & & & Message & \\
\hline 5. & Ms. & Diabetes & Normal & Normal & $\begin{array}{l}\text { High } \\
(2015)\end{array}$ & $\begin{array}{l}\text { Glucose } \\
\text { level is } \\
\text { high: } \\
\text { Emergency } \\
\text { Message }\end{array}$ & $\begin{array}{l}\text { High } \\
\text { Glucose } \\
\text { level }\end{array}$ \\
& & & & & & \\
\hline
\end{tabular}

* Includes Mr. ABC, Ms. XYZ, Mr. PQR \& Ms. DEF

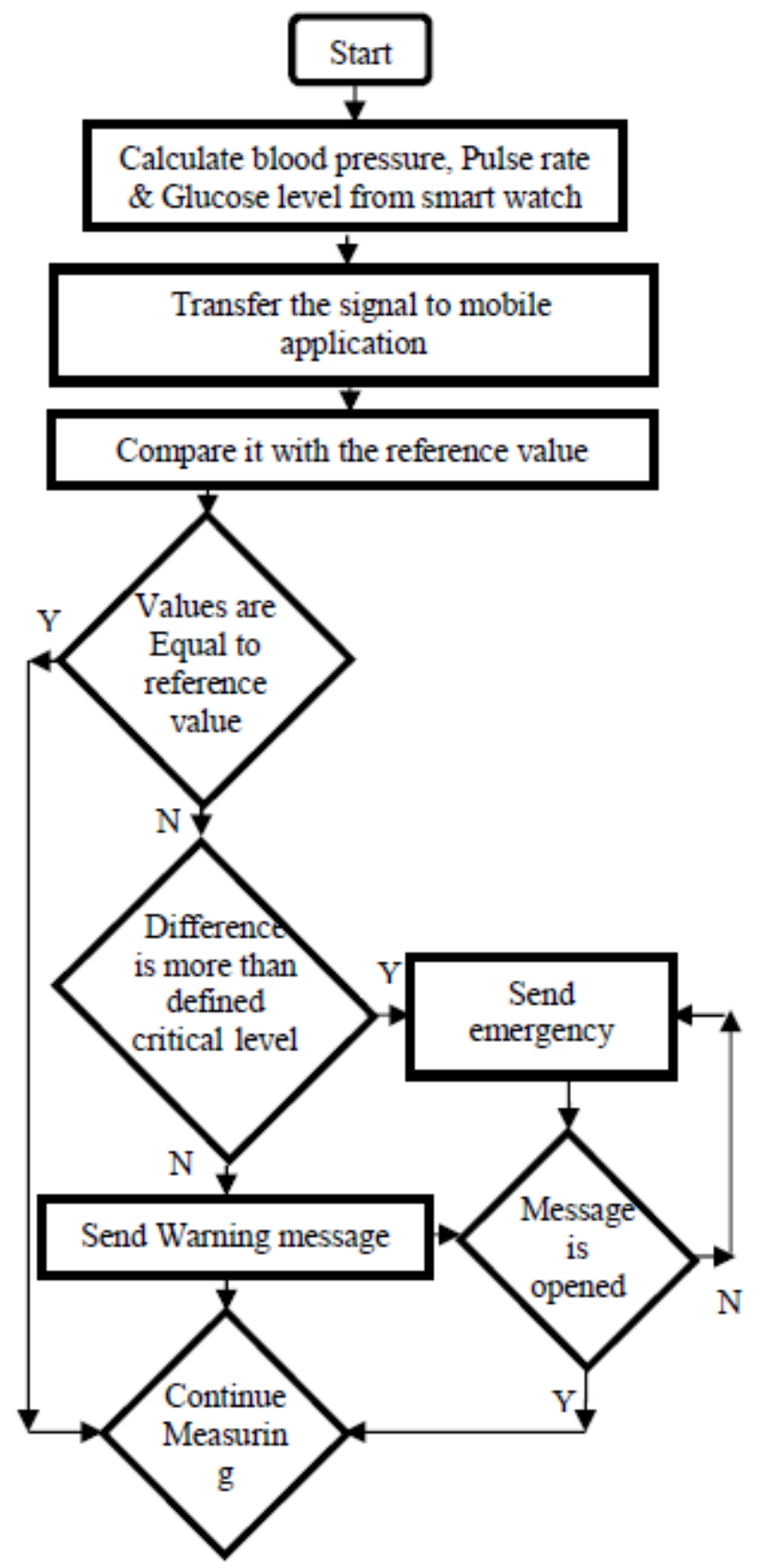

Figure 1. Computing flow chart

\section{Objectives of the proposed project}

The proposed study aims at

1. To enhance Health communication with the help of mobile phone.

2. To give fast and accurate reading

3. It will help the family member to know about if there is any emergency with their loved once. 
DOI: $10.21522 /$ TIJAR.2014.04.02.Art026

ISSN: 2520-3088

4. Provides reminder message if someone miss the first message.

\section{Benefit to society}

1. It will reduce the sudden death rate.

2. Provide the location and details of the patient.

3. Let others know about the emergency condition so that first aid can be provided timely.

4. Rapid diagnose will help to provide first aid immediately.

\section{Future plans}

Further it can be extended to diagnoses more diseases. The location of the nearest hospital can also be send to the user's so that he/she can be rushed to nearest hospital without any delay. Cloud storage can be linked so that patient's history can be saved.

\section{References}

[1] Caroline Free, Gemma Phillips, Louise Watson, Leandro Galli, Lambert Felix, Phil Edwards, Vikram Patel, Andy Haines "The Effectiveness of Mobile-Health Technologies to Improve Health Care Service Delivery Processes: A Systematic Review and Meta-Analysis" PLOS Medicine, Volume 10, Issue 1 January, 2013.

[2] Eliza Strickland "How mobile helth app and wearable could make actually people more sicker," Spectrum. IEEE, vol. A247, pp. 529-551, February 2017.

[3] Hoang D. Nguyen \& Danny Chiang Choon Poo, "Analysis and design of mobile health interventions towards informed shared decision making: an activity theory-driven perspective" Taylor \& Francis ISSN: 1246-0125 (Print) 2116-7052 (Online) Journal.

[4] Selime Ozaktas1, Feyza Galip2, Ibrahim Furkan Ince3, Md. Haidar Sharif4, "An Automatic Monitoring System For Vehicle Drivers," (IJSRISE) Turkey Volume 2, Issue 1, April-2016. ISSN 2380-8128.

[5] Yousuf Gandapur, Sina Kianoush, Heval M. Kelli, Satish Misra, Bruno Urrea Michael J. Blaha, Garth, Francoise A., and Seth S. Martin "The role of mHealth for improving medication Adherence in patients with cardiovascular disease: a systematic review," Received 17 February 2016; revised 5 April 2016; accepted 6 April 2016. 